\title{
Migrant Women's Use of Modern Contraception in Cotonou, Benin Republic
}

\author{
Boladé Hamed Banougnin ${ }^{1}$, Adeyemi Olu Adekunle², Adesina Oladokun², \\ Mouftaou Amadou Sanni ${ }^{3}$ \\ ${ }^{1}$ Pan African University, Life and Earth Sciences Institute (Including Health and Agriculture), University of Ibadan, Ibadan, Nigeria \\ ${ }^{2}$ University College Hospital, Department of Obstetrics and Gynaecology, University of Ibadan, Ibadan, Nigeria \\ ${ }^{3}$ Graduate School of Statistics and Demography, University of Parakou, Parakou, Benin Republic
}

\section{Email address:}

bbanougnin0192@stu.ui.edu.ng (B. H. Banougnin)

\section{To cite this article:}

Boladé Hamed Banougnin, Adeyemi Olu Adekunle, Adesina Oladokun, Mouftaou Amadou Sanni. Migrant Women's Use of Modern Contraception in Cotonou, Benin Republic. American Journal of Biomedical and Life Sciences. Vol. 6, No. 5, 2018, pp. 103-112. doi: 10.11648/j.ajbls.20180605.12

Received: October 9, 2018; Accepted: October 24, 2018; Published: November DD, 2018

\begin{abstract}
Evidence shows that migration, especially from rural areas and small cities to large cities, has critical consequences for sexual and reproductive health services utilization. Very few studies address the issue of contraceptive use among internal migrants in cities of sub-Saharan Africa countries, partly because of the limitations of available data. This study aimed to investigate the associations between migration status and modern contraceptive use and to examine whether and how the effect of migration status changes when it is disaggregated by length of residence, and reason for migration. Data from a survey conducted in Cotonou, the largest city of Benin Republic, from March-May 2018 were used. The study enrolled 792 (1,068 weighted) sexually active women, with the exception of those who reported being pregnant at the time of the survey. The socio- economic and demographic characteristics of the sample were described - this include the percentage of migrants, the length of residence and whether the migration was for school or job reason. Finally, a set of three logistic regression models were computed. These models present: (i) the crude effect of migration on modern contraceptive use, (ii) the effect of migration on modern contraceptive use after adjusting for socio- economic and demographic characteristics, and (iii) the joint effect of migration and reason for migration on modern contraceptive use-while still controlling for socio- economic and demographic characteristics. The results firstly show that there was non-significant association between internal migration and modern contraceptive use. Then, statistically significant differences emerged when migration status is interacted with reason for migration. Migrants in Cotonou for school or work motive had the highest probability of using modern contraception $(32 \%)$, compared with the other groups (predicted probability values ranging from $17 \%$ to $21 \%$ ). In conclusion, disaggregating migration status by reason for migration leads to better understanding of the effect migration status has on modern contraceptive use.
\end{abstract}

Keywords: Internal Migration, Contraception, Cotonou, Benin Republic

\section{Introduction}

Empirical evidence from sub-Saharan Africa shows an urban advantage in terms of contraceptive use. Contraceptive use levels in cities are generally higher than those of rural areas [1-5]; which is in line with studies suggesting that rural inhabitants experience poorer reproductive health status than urban dwellers [6]. In most of sub-Saharan Africa countries, where the economies are predominantly rural [7], access to, or availability of reproductive health services is still problematic $[8,9]$. As an immediate result, the pace of the decline in fertility rates is not sufficient as such to sustain economic growth and reduce poverty $[10,11]$.

In Benin Republic, a predominantly rural country [12], the level of modern contraceptive use is among the lowest in sub-Saharan Africa, and the fertility rate is moderately high [13]. As reported in the 2012 Demographic and Health Survey (DHS) report, 7.9\% of married women were using 
modern contraceptive methods, and the total fertility rate (TFR) was 4.9 children per woman [14]. These national figures conceal disparities between urban and rural areas. About 7 percent of rural women of reproductive age (15-49 years) were using a modern contraceptive method, compared with 10 percent of urban women [14]. The TFR in rural areas was 5.4 children per woman, compared with 4.3 in urban areas [14]. The current TFR is lower than that of 2006 where each woman had 5.7 children on average [13].

Like in many sub-Saharan Africa countries, the decline in fertility observed in Benin Republic occurred in a context of growing urbanization. In Benin Republic, the urbanization rate has increased from $34 \%$ in 1990 [15] to $45 \%$ in 2013 [12]. Engel, Richter [16] have shown that the increased urbanization in Benin Republic is mainly driven by migrations from rural to urban areas. Also, migration from rural areas to cities is shifting the rural-urban balance of the population of Benin Republic. In consequence, the urbanization rate of the country will probably reach $61 \%$ according to demographic projections of the United Nations [15]. Moreover, Anglewicz, Corker [17] suggested that ruralto-urban migration could have implications for population health. Migration to cities could either increase or decrease urban inequities in contraceptive use between migrants and non-migrants $[17,18]$. In this regard, it is critical to know how migrants contribute to contraceptive uptake in cities; so, national policymakers and programme implementers can take appropriate action to improve family planning services utilization.

How migration to cities affects fertility as well as reproductive health issues has been extensively studied by demographers and other scientists [19-21]. However, there are very few studies on contraceptive use among migrants $[18,22]$. This lack of attention is partly due to the relative scarcity of surveys that collect detailed data on both migration and contraceptive use [23]. For example, many DHS data do not include any direct question on migration. Some DHS data record the childhood place of residencefrom which researchers can approach the concept of migration - but not the duration of stay in the current place of residence [24]. Nevertheless, the 2012 Benin Republic DHS includes questions on migration and duration of stay, even though it is only in the household questionnaire [14]. Although statistical matching techniques provide a way to merge data coming from household and women questionnaire into a unique database, some bias can occur. Indeed, within the same household, information provided by the household respondent may be different from those provided by eligible respondents for any individual questionnaire.

The main contribution of the study is to use suitable data recording migration and birth histories as well as family planning use information in order to address appropriately migrant women's use of modern contraception. The study location is Cotonou - the largest city of Benin Republic, where the high levels of immigration [12] coexist with inequities in access to and utilization of family planning services [14]. Basing on data from the Cotonou Fertility and Migration Survey (FMS), the study examines modern contraceptive use among migrant and non-migrant women. Findings from this work will guide stakeholders that seek to influence family planning use, especially among the most vulnerable groups.

Research has identified migration as a life changing event with critical consequences for sexual and reproductive health services utilization [19-21]. Researchers suggest three main models or hypotheses for explaining differentials in contraceptive use between migrants and non-migrants: the adaptation hypothesis, the selection hypothesis and the disruption hypothesis [19-21, 23, 25, 26]. These hypotheses differ in several respects, the main difference being in the relationship between the timing of migration and change in the behaviours of migrants towards contraception. On the other hand, the three hypotheses are partly complementary and partly contradictory.

First, the adaptation model postulates that the higher utilization of contraception among migrant women in cities results from their adaptability to new socio-economic and environmental constraints [23, 26, 27]. The living conditions in cities favour low fertility and an increased use of modern methods of contraception. Brockerhoff [25] was one of the first authors to test the adaptation hypothesis in the African context. The author found that the odds of modern contraceptive use generally increased among migrants in cities around the time of migration, and remained high in the long run among most migrant groups. Research attributes the increase in modern contraceptive use among migrants to a high access to mass media education, urban living, and higher economic status, among others [28]. In Bangladesh for instance, Kamruzzaman and Hakim [29] found that urban areas provide greater exposure to information about family planning through print and broadcast media. However, it takes time before migrants adapt to reproductive behaviours in cities. The accumulation of knowledge and the expansion of the range of social contacts in the new urban environment occur over time [30]. On behalf of the adaptation theory, migrants in Cotonou are initially expected-in a relatively short-term - to be less likely to use modern contraceptives than non-migrants in Cotonou (Hypothesis 1a). Then, with time passing, no significant difference in modern contraceptive use between migrants and non-migrants in Cotonou is expected (Hypothesis 1b).

Second, the selection model defines migrants in cities as a self-selected group with socioeconomic characteristics different from those of non-migrants in rural areas [23, 27]. The socioeconomic characteristics of migrants in urban areas predispose them to a preference for smaller families, and consequently greater odds of modern contraceptive use [26]. Particularly, empirical findings support that the higher level of contraceptive use among rural-urban migrants is mainly due to their higher socioeconomic status [23, 26, 27]. Migrants in cities are usually well-educated, often move to cities in search of well-paying jobs; which can lead to a delay in childbearing [31-33] and an increase in modern 
contraceptive use [20, 27]. Ochako, Askew [27] have pointed out a non-significant difference in modern contraceptive use between migrants and non-migrants in urban areas of Kenya. The authors have attributed this result to the specific high socioeconomic status of women who migrated to urban areas. Several other studies in sub-Saharan have found that migrants and non-migrants in cities have similar high socioeconomic and demographic characteristics [1, 21, 34]. Just like these sub-Saharan Africa countries, migrant women in Cotonou are supposed to have socio- economic and demographic characteristics relatively similar to those of non-migrant women in Cotonou. In consequence, after adjusting for women' socio- economic and demographic backgrounds, migrant and non-migrant women in Cotonou are expected to have similar odds of using modern contraceptives (Hypothesis 2).

Third, the disruption theory suggests that certain migrations implying temporary spousal separation lead to delays in childbearing $[20,26,35,36]$. One of the first developments of this theory resulted from a study carried out by Goldstein and Tirasawat [37] on the analysis of migrants' fertility in urban areas of Thailand. It was not until years later that some researchers tested the disruption hypothesis while focusing on family planning use among migrants [23, 25-27, 38]. Most of them showed that temporary labour migrants, for example, were more likely to use modern contraception, particularly as some of them were involved in extra-marital relations. In consequence, migration for economic reasons might contribute to an increase in contraceptive use, at least in the short-term. Moreno [38], Lindstrom and Hernández [23], and Ochako, Askew [27] confirmed the disruption hypothesis respectively in northeaster Brazil, Guatemala and Kenya. They argued that the higher likelihood of contraceptive use among migrants in cities reflects the possible disruptive nature of migration on childbearing. In line with these research findings, migrants for job or school reason are expected to have the highest odds of using modern methods of contraception (Hypothesis 3 ).

\section{Methods}

\subsection{Source of Data}

This paper used data from the Fertility and Migration Survey (FMS) conducted in Cotonou from March-May, 2018. The survey used a sampling strategy stratified by Cotonou's 13 arrondissements (administrative districts) to select a total of 56 enumeration areas (EAs). The EAs were drawn from the sampling frame from the 2013 General Census of Population and Housing. After listing and mapping each EA, 35 households were selected randomly per EA. Occupants in selected households were enumerated and eligible women of reproductive age (15-49 years) were contacted and considered for interview. The sample size is 1907 complete household surveys and 1933 complete female surveys. The survey gathers data on migration history, childbearing, fertility preference, family planning and other socio- economic and demographic variables. Especially, the migration history section contains information on locations where respondents previously lived. It also includes the year and month in which they moved to Cotonou, along with reasons for the migration. Moves that took place within Cotonou and those from other countries were excluded from the analysis. The final sample used consists of $792(1,068$ weighted) currently sexually active women, with the exception of those who reported being pregnant at the time of the survey.

\subsection{Variables}

The dependent variable is the current use of any modern method of contraception. It is a binary variable taking the value of 1 if the woman reported using a modern method of contraception and 0 otherwise. Modern contraceptive methods include pill, intrauterine device, injectables, female condom, male condom, female sterilization, male sterilization, implants and lactational amenorrhea as classified by the DHS program [39].

The main independent variable of the study is the migration status. Drawing on the work of Garcia, Pindolia [40], information on the previous place of residence and duration of residence of women in Cotonou, were used to define migration. Migrants in this study are women who were living in Cotonou at least six months before the survey and who were residing somewhere else-in Benin Republic-previously. Migrants were then classified into two groups: recent migrants and earlier migrants. Migrants who spent up to ten years in Cotonou at the time of the survey were considered as recent migrants. And those who spent more than ten years were considered as earlier migrants. This classification helps to test the gradual process of adaptation as suggested by many researchers when studying the relationship between migration and reproductive behaviours [18, 21, 26, 33, 35].

Other socio- economic and demographic variableseducation among others - have also been found to greatly affect modern contraceptive use as well [41-43]. Some authors who analyzed the effect of migration on contraceptive use have repeatedly used these variables in order to control for selective migration [18, 21, 23, 27, 44]. In this work, the other key independent variables are media exposure, education, fertility preference and religion. The variable of media exposure is a composite indicator including the frequency of: reading newspaper or magazine, listening to radio and watching television. Principal components analysis (PCA) method was employed to assign the indicator weights that enabled to generate the media exposure index. Filmer and Pritchett [45] recommended this technique for constructing index values. This procedure first standardizes the indicator variables (calculating Z-scores); then the factor coefficient scores (factor loadings) are calculated; and finally, for each observation, the indicator values are multiplied by the scores and summed to produce the observation's index value. DHS experts use this technique on behalf of the construction of the DHS wealth index. Here, the first factor was used to represent the media exposure index. The media 
exposure index has two categories: low exposure and high exposure (see Appendix for statistical summary). Age and number of living children are used as control variables. Finally, interaction terms were created using the motive for living in Cotonou and migration status.

\subsection{Analyses}

Binary logistic regression models were used to estimate how internal migration and other socio- economic and demographic variables affect modern contraceptive use in Cotonou. Findings were presented through three different models. The first model presents the effect of migration on modern contraceptive use. The second model shows the relationship between migration and modern contraceptive use, after adjusting for the socio- economic and demographic variables mentioned above. The second regression model enables to see whether the odds of modern contraceptive use could be affected by the selective character of migration. Finally, interaction terms constructed from the combination of migration status and motive for living in Cotonou were introduced in the third model. This model enables to test the disruption hypothesis. Results are presented as odds ratios and, in the case of the interactions, as predicted probabilities. All models are presented after controlling for age and number of living children.

\section{Results}

First, some descriptive statistics of the variables used in the analysis are presented in Table 1 . There is no missing value for any of the variables. Table 1 indicates that the sample had more migrant women $(59.06 \%$ including recent migrant women and earlier migrant women-32.94\% and $26.12 \%$ respectively) than non-migrant women (40.94\%). Few of the women (13.95\%) were living in Cotonou exclusively for school or job motive. At the moment of the survey, only 2 in 10 women were using modern contraceptive methods. Most of the respondents $(72.06 \%)$ have attained at least a primary education. Approximatively two-thirds $(64.09 \%)$ of the women had a high exposure to media through magazine, radio and television. At the time of the survey, the respondents were, on average, 31 years old; most of them were non-Muslims (85.80\%); and more than one half $(55.98 \%)$ wanted to have at least four children.

Table 1. Distribution of the dependent variable and independent variables: percentages / mean (standard deviations).

\begin{tabular}{lcl}
\hline Variable & \% / Mean (SD) & Observations \\
\hline Modern contraception & & \\
User & 79.51 & 849 \\
Non-user & 20.49 & 219 \\
Migration status & \\
Non-Migrant & 40.94 & 437 \\
Recent migrant & 32.94 & 352 \\
Less recent migrant & 26.12 & 279 \\
Living in Cotonou for work or school motive & \\
Yes & 13.95 & 149 \\
No & 86.05 & 919 \\
\hline
\end{tabular}

\begin{tabular}{lll}
\hline Variable & \% / Mean (SD) & Observations \\
\hline Education & & \\
No education & 27.94 & 298 \\
Primary & 28.08 & 300 \\
Secondary or higher & 43.98 & 470 \\
Media exposure & & \\
Low & 35.91 & 384 \\
High & 64.09 & 684 \\
Fertility preference & & \\
$0-3$ & 44.02 & 470 \\
4 or more & 55.98 & 598 \\
Religion & & \\
Muslim & 14.20 & 152 \\
Non-Muslim & 85.80 & 916 \\
Living children & & \\
None & 23.87 & 255 \\
1-2 & 40.09 & 428 \\
3-4 & 28.91 & 309 \\
5 or more & 7.13 & 76 \\
Woman's age (15-49) & $31.00(7.56)$ & 1068 \\
Number of observation & 1,068 & \\
\hline
\end{tabular}

Note: $\%=$ percentage; $\mathrm{SD}=$ standard deviation

Source: Fertility and Migration Survey, Cotonou, 2018

Next, Table 2 (Model 1-3) and Figure 1 (Model 3) present the results of the multivariate analysis. All models were initially controlled for age and number of living children. These models may be summarized as follows.

Shows the relationship between migration and

Model 1. modern contraceptive use. It gives an insight into the hypothesis of adaptation (Hypothesis 1).

Model 1 plus four other socio- economic and

Model 2. demographic variables. This model enables to test the selection hypothesis (Hypothesis 2).

Model 2 with migration status variable being

Model 3. replaced by interaction terms. Hypothesis 3 (disruption hypothesis) is tested through Model 3.

\subsection{Adaptation Hypothesis}

The hypothesis regarding adaptation proposed that migrants adapt to non-migrants' contraceptive behaviour, but gradually. It was expected that, few time after moving to Cotonou, migrants would be less likely to use modern contraceptive methods than non-migrants in Cotonou (Hypothesis 1a). And, with time passing, no significant difference in modern contraceptive use between migrants and non-migrants in Cotonou was expected (Hypothesis 1b). Findings corresponding to Model 1 in Table 2 show that the odds of using modern contraceptive did not differ significantly between recent migrants (odds ratio $=0.78$, pvalue $>0.10$ ) and non-migrants. Likewise, migrant women who spent more than ten years in Cotonou had almost similar odds of using modern methods of contraception (nonsignificant odds ratio of 0.78 ) as non-migrant women. These results partially confirm Hypothesis 1. The adaptation process depicted in Model 1 in Table 2 is of a short-term rather than a long-term nature. The rapid adaptation of migrants may also be due to a selective migration of women who have preferences for smaller families. 


\subsection{Selection Hypothesis}

Hypothesis 2 expected non-significant effect of migration on modern contraceptive use after adjusting for women's socio- economic and demographic backgrounds - and regardless of how long migrants have resided in Cotonou. So, women's background variables were included in the analysis to further control for selective character of migration. Although non-significant, the differences of odds between migrants and non-migrants have decreased from 0.22 (in Model 1 in Table 2) to 0.13 (in Model 2 in Table 2). This result may be due to further selectivity of migrant women that is unobserved in this case. As shown in Table 2, Model 2 fit improves significantly. Indeed, the likelihood ratio test statistic value has increased from 34.91 (global $\mathrm{p}$-value $=$ 0.0000 ) in Model 1 to 58.20 (global p-value $=0.0000$ ) in Model 2. Thus, migrant women (some of them, at least) have unobserved characteristics that increase their odds of modern contraceptive use. Controlling for this unobserved selectivity, however, does not change the previous results substantially. It can be established that some migrations are directly related to a delay in childbearing and therefore, an increase in modern contraceptive use. In other words, the figures obtained from Model 2 are supportive of the selection hypothesis, but the adaptation hypothesis still holds. These findings are consistent with Hypothesis 2 (selection hypothesis).

Table 2. Logistic regression models predicting modern contraceptive use. Odds ratios and predicted probabilities for the interaction effects (displayed in Figure 1).

\begin{tabular}{|c|c|c|c|}
\hline Variable & Model 1 & Model 2 & Model 3 \\
\hline & Odds ratios & Odds ratios & Odds ratios \\
\hline \multicolumn{4}{|l|}{ Migration status } \\
\hline Non-Migrant & Ref. & Ref. & \\
\hline Recent migrant & 0.78 & 0.87 & \\
\hline Less recent migrant & 0.78 & 0.87 & \\
\hline \multicolumn{4}{|l|}{ Education } \\
\hline No education & & Ref. & Ref. \\
\hline Primary & & 1.39 & 1.42 \\
\hline Secondary or higher & & $1.82 * * *$ & $1.73 * *$ \\
\hline \multicolumn{4}{|l|}{ Media exposure } \\
\hline Low & & Ref. & Ref. \\
\hline High & & 1.30 & 1.33 \\
\hline \multicolumn{4}{|l|}{ Fertility preference } \\
\hline $0-3$ & & Ref. & Ref. \\
\hline 4 or more & & $0.66 * *$ & $0.65^{* * *}$ \\
\hline \multicolumn{4}{|l|}{ Religion } \\
\hline Muslim & & Ref. & Ref. \\
\hline Non-Muslim & & 0.77 & 0.80 \\
\hline \multicolumn{4}{|l|}{ Living children } \\
\hline None & Ref. & Ref. & Ref. \\
\hline $1-2$ & 0.86 & 0.95 & 0.98 \\
\hline $3-4$ & 1.34 & $1.87 * *$ & $1.94 * *$ \\
\hline 5 or more & $2.17 * *$ & $3.31^{* * *}$ & $3.33^{* * *}$ \\
\hline \multirow[t]{2}{*}{ Woman's age } & $0.94 * * *$ & $0.93 * * *$ & $0.93^{* * *}$ \\
\hline & & & Predicted Probability [CI min.; max.] $]^{(a)}$ \\
\hline \multicolumn{4}{|c|}{ Migration * Motive for living in current location } \\
\hline Migrant * Job/Edu & & & $0.32[0.23 ; 0.40]$ \\
\hline Migrant $* \neq(\mathrm{Job} / \mathrm{Edu})$ & & & $0.17[0.13 ; 0.20]$ \\
\hline Non-mig $*$ Job/Edu & & & $0.17[0.06 ; 0.29]$ \\
\hline Non-mig * $\neq($ Job/Edu $)$ & & & $0.21[0.18 ; 0.24]$ \\
\hline Observations & 792 & 792 & 792 \\
\hline Degree of freedom & 6 & 11 & 12 \\
\hline Likelihood ratio & 34.91 & 58.20 & 69.43 \\
\hline P-value & 0.0000 & 0.0000 & 0.0000 \\
\hline
\end{tabular}

Note: $\mathrm{CI}=$ confidence interval; $\mathrm{Job} / \mathrm{Edu}=$ who are in Cotonou for work or school reason;

$\neq(\mathrm{Job} / \mathrm{Edu})=$ who are in Cotonou neither for work, nor for school reason; Ref. $=$ Reference

category; For odds ratios, $* * * \mathrm{p}<0.01, * * \mathrm{p}<0.05, * \mathrm{p}<0.1$

(a) All predicted probabilities are significant at 0.0000

Source: Fertility and Migration Survey, Cotonou, 2018

\subsection{Disruption Hypothesis}

In Model 3 in Table 2, interaction terms between migration and motive for living in Cotonou are included. Hypothesis 3 suggested that migrants for job or school motive would have the highest chances of using modern contraception. The 
effects of interactions on modern contraceptive use are presented in Figure 1. Consistent with Hypothesis 3, Figure 1 shows that women who migrated to Cotonou for school or job motive had the highest probability of using modern contraception (32\%), compared with the other groups (predicted probability values ranging from $17 \%$ to $21 \%$ ). These probability values are significant. The model fit has, however, improved (likelihood ratio of 69.43 and p-value is $0.000)$, pointing the validity of the selection hypothesis. On the other hand, findings from Model 1 and Model 2 in Table 2 support a probable complementarity between the selection and adaptation hypotheses. Therefore, the three hypotheses are probably complementarity.

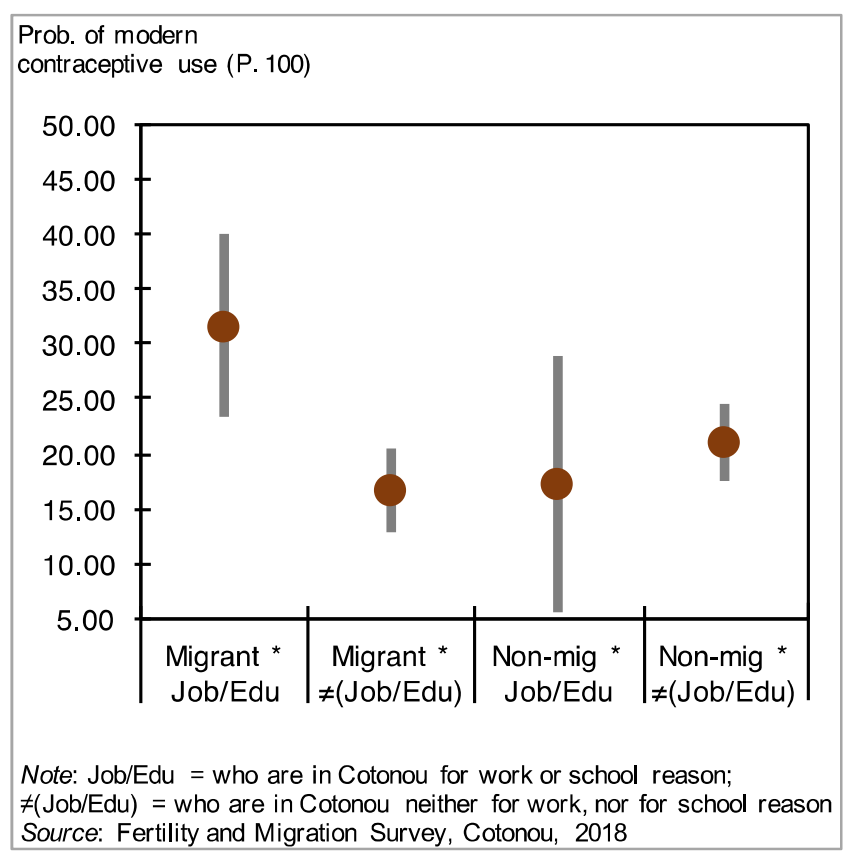

Figure 1. Effect of internal migration on modern contraceptive use in Cotonou, Benin Republic. Predicted probabilities (with 95\% confident interval limits) of interaction terms between migration status and motive for living in Cotonou.

\subsection{Other Variables}

Finally, other variables such as education, age, fertility preference and number of living children had significant effect on modern contraceptive use. Women wanting at least four children by the end of their reproductive life were $35 \%$ less likely to use modern contraception than those wanting less. The higher the educational level and the number of living children, the higher the odds of modern contraceptive use. Particularly, women with secondary education were 1.73 times more likely to use modern methods of contraception than their peers with primary education or less. There is an increased likelihood to use modern contraceptives for women with 3-4 children (1.94 times) and more than four children (3.33 times) compared to those with less than three children. And, the older the woman, the lower the odds of modern contraceptive use. The odds of using modern methods of contraception decrease by $7 \%$ per one-year increase in the age, all other factors being equal.

\section{Discussion}

This research contributes to the literature on the relationship between migration and reproductive health services utilization. In particular, this study analyses the effects of internal migration on modern contraceptive use in Cotonou, the largest city of Benin Republic. It examines how internal migration affects modern contraceptive use through the adaptation, selection and disruption models. As previous research has shown, migration produces significant changes in reproductive health services utilization. Using three different logistic regression models, the findings of this study enable to validate the selection hypothesis, the disruption hypothesis and partially, the adaptation hypothesis. These hypotheses are probably complementary. Additionally, women with secondary education or higher, desiring less than four children, having more than two children and those younger in age had increased odds of using modern contraceptive methods.

Firstly, in a relatively short-time, migrant women adapt their preferences and behaviours to those of the host society (Cotonou). As a result, the modern contraceptive use behaviour of migrant women tends to converge rapidly rather than gradually to that of non-migrants in Cotonou. The adaptation model depicted in recent studies on the relationship between migration and contraceptive use are often gradual rather than rapid [23, 27]. The authors of these studies attribute the gradual nature of the adaptation to the time it takes for migrants in cities to learn about modern contraceptive methods. Other researchers have also pointed that the adaptation process may be faster than expected [46]. Comparing fertility levels of immigrants in Sweden to those of the Swedish-born population, Andersson [47] arrived at conclusions that support the idea of relatively rapid adaptation of immigrants to childbearing behaviour that prevails in the country of destination. The short-term nature of adaptation may be due to the selective character of migration of women whose fertility preferences are more similar to those of Cotonou dwellers. It may also be due to the disruption effect that seems incompatible with childbearing after migration. Moreover, like Cotonou natives, migrants encounter place-specific cost constraints on childbearing. Future research might aim to identify precisely at what duration of stay in Cotonou migrants and nonmigrants have similar odds of using modern methods of contraception.

Secondly, when controlling for women' socio- economic and demographic backgrounds, Model 2 fit improved. And, although non-significant, the differentials in the odds of modern contraceptive use between migrants and nonmigrants decreased consistently; which may reflect the advantageous effects of a selective migration towards modern contraceptive use. Migrant selection effect proposes that migrants are a special group of people with specific social and economic characteristics similar to those of people at destination. Indeed, just as urban natives, migrants to cities are not randomly constituted and they have preferences for 
smaller family size. Thus, the specific social and economic traits of migrants, especially in urban areas, facilitate the utilization of modern contraceptives [18, 22, 27], thereby reducing the gap in modern contraceptive use between migrants and migrants in cities. Generally, migrants in Cotonou are more educated and have high access to media. Most of them usually move to Cotonou for job and school opportunities as well as other economic reasons; which may account for the delay in childbearing and consequently, increased odds of using modern contraceptive methods. This explanation found support in a work conducted by Rokicki, Montana [33] on the association between migration and pregnancy outcomes among women in urban slums of Accra. On the other hand, the likelihood of rapid adaptationhighlighted in this work-supports the continued consideration of the way in which the adaptation and the selection hypothesis compete. It points to the need for more research on the relationship between migration and reproductive behaviour through a competing view of adaptation and selection models.

Thirdly, the fact that migrant women for job or school reason have the highest predicted probability of using modern contraceptives is consistent with the disruption hypothesis. The migration process itself is, in some ways, disruptive of childbearing, at least in the short-term. The resulting delay in childbearing may, however, be compensated for, either after longer period of settlement or once the migration is complete $[32,48]$. So, migrants in Cotonou show particularly high levels of modern contraceptive use due to the possible disruptive factors associated with the migration process. Moreover, being nonmigrants or being migrants for purposes other than those for job or school does not make much difference with regard to modern contraceptive use. Therefore, it can be argued that newcomers for job or school reason delay their childbearing - by using modern family planning methodsin order to achieve their main goal (work or studies). Then, after a certain period of settlement in Cotonou, the latter adapt so that, they have similar odds of using modern contraceptives as their non-migrant peers. There may also be other reasons for the disruptive character of the migration process. A move for economic reasons may be sufficiently disruptive from a socio-psychological perspective as to interfere with the physiological capacity to bear children [49]. The "non-readiness" of bearing children among migrant women for economic reasons favours their acceptance and use of modern contraceptive methods. The disruption model can also directly operate through spousal separation. Research has shown that the fear of extramarital pregnancy account for modern contraceptive use among migrant women $[50,51]$. Further research should assess the extent to which migration generating spousal separation affects the utilization of family planning methods.

\section{Conclusion}

Internal migration plays an important role in explaining the population dynamics which consequently influence the population structure and distribution as well as reproductive health services use [21, 35]. Despite this important role, internal migration receives low priority by policymakers in Benin Republic and other sub-Saharan Africa countries [20, $21,26,27]$. Therefore, family planning use among migrants remains of interest to policymakers, due to its influence on fertility, sexual and reproductive health and the implications for provision of appropriate services [27, 52]. The evidence from the findings can be useful to policymakers and programme implementers to help inform future interventions. It also helps to improve health services among various categories of the population in Benin Republic, especially those who are vulnerable [53] such as migrant women who are not involved in any socioeconomic activity. Moreover, disaggregating migration status by reason for migration leads to better understanding of the effect migration status has on modern contraceptive use. Programmatically, the differentials in modern contraceptive use by migration status should be considered when designing family planning programmes. This responses to family planning needs of migrant and nonmigrant women.

The main contribution of the study is the use of suitable data on lifetime migration (including place of birth, previous place of residence, duration of residence, and reason for migration) and family planning use to address appropriately migrant women's use of modern contraception. Unlike many commonly used data (DHS among others) to addressed the relationship between migration and fertility (and fertilityrelated indicators), this study relied on collected data on migration from both household (for every household member including women of reproductive age) and women's questionnaires. Indeed, some DHS data (e.g., 2012 Benin Republic DHS data) include questions on migration, but only in the household questionnaire (see an example in [14]). And, although statistical matching techniques provide a way to merge data coming from household and women questionnaire into a unique database, some bias can occur. In fact, within the same household, information provided by the household respondent may be different from those provided by eligible respondents for any individual questionnaire. Then, instead of analysing the migration-contraception relationship through a single model like in many studies [17, $23,27]$, the analysis methods in this study were based on three different models, each addressing a single hypothesis (gradual adaptation, selection or disruption). The major limitation of this study is that it cannot establish a causal relationship between migration and modern contraceptive use. This would require longitudinal data that include at different time-points information on both fertility and migration. 


\section{Appendix}

Table 3. Distribution of media exposure's variables by coordinates of the first and second dimensions of the principal component analysis.

\begin{tabular}{lll}
\hline Variable & Coordinates of the $\mathbf{1}^{\text {st }}$ dimension & ${\text { Coordinates of the } \mathbf{2}^{\text {nd }} \text { dimension }}^{\text {Frequency of reading newspaper or magazine }}$ \\
Not at all & -0.5 & 0.4 \\
Less than once a week & 0.5 & 0.2 \\
At least once a week & 0.2 & -0.6 \\
Frequency of listening to radio & & -0.3 \\
Not at all & -0.1 & 0.3 \\
Less than once a week & 0.5 & 0.0 \\
At least once a week & -0.2 & -0.4 \\
Frequency of watching television & & 0.1 \\
Not at all & -0.1 & 0.2 \\
Less than once a week & 0.4 & \\
At least once a week & -0.2 & \\
& & \\
\hline
\end{tabular}

Source: Fertility and Migration Survey, Cotonou, 2018

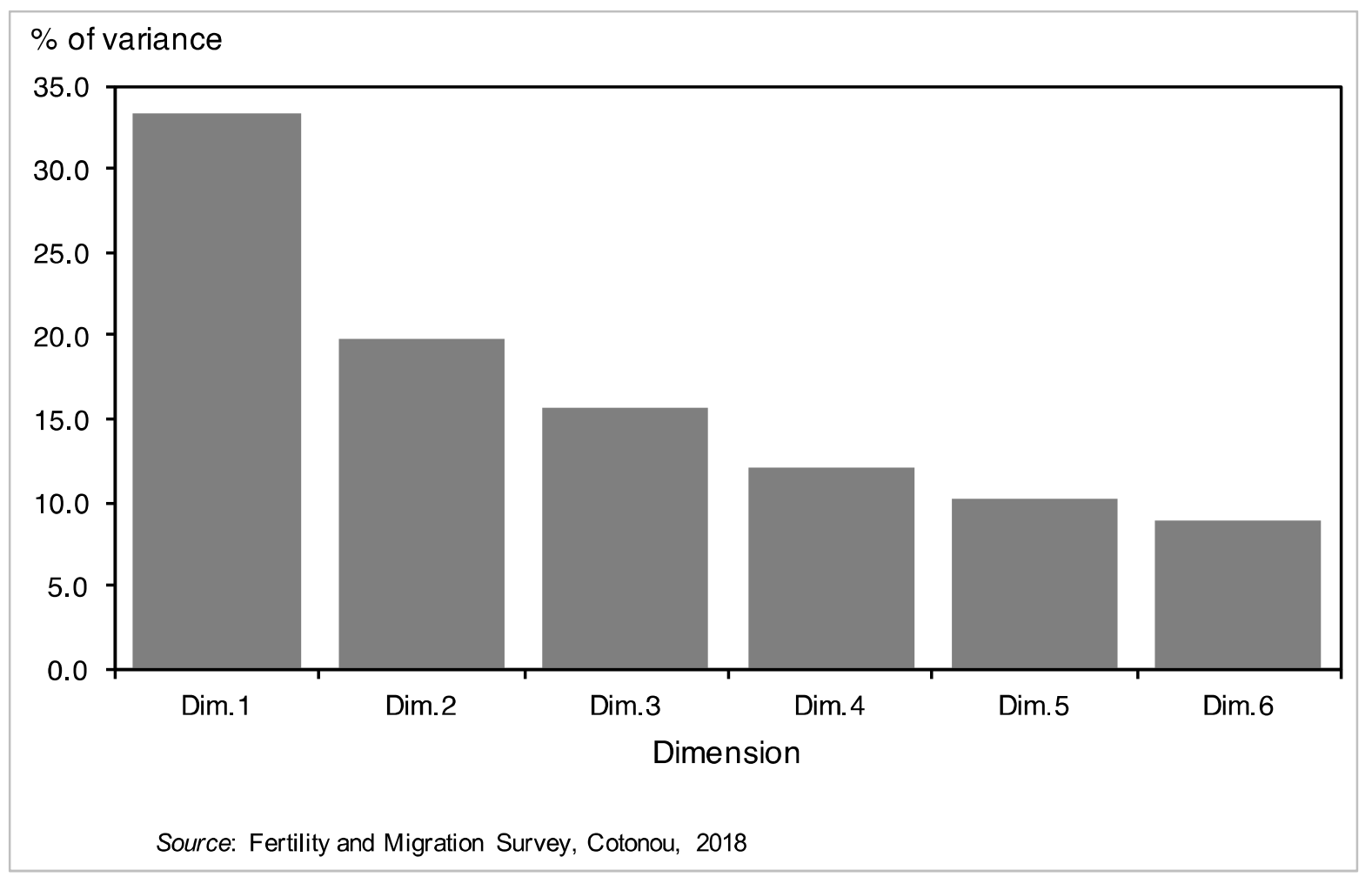

Figure 2. Plot of eigenvalue.

\section{References}

[1] Mberu, B., D. Béguy, and A. C. Ezeh, Internal Migration, Urbanization and Slums in Sub-Saharan Africa, in Africa's Population: In Search of a Demographic Dividend. 2017, Springer. p. 315-332.

[2] Beguy, D., et al., Changes in Use of Family Planning among the Urban Poor: Evidence from Nairobi Slums. Population and Development Review, 2017. 43(S1): p. 216-234.

[3] Okigbo, C., et al., A multilevel logit estimation of factors associated with modern contraception in Urban Nigeria. World Medical \& Health Policy, 2017. 9(1): p. 65-88.
[4] Berhanu, B., Fertility and Contraceptive use in rural Dalle, southern Ethiopia. The Ethiopian Journal of Health Development (EJHD), 2017. 8(1).

[5] Gueye, A., et al., Belief in family planning myths at the individual and community levels and modern contraceptive use in urban Africa. International perspectives on sexual and reproductive health, 2015. 41(4): p. 191.

[6] Chintsanya, J., Trends and correlates of contraceptive use among married women in Malawi: Evidence from 2000-2010 Malawi Demographic and Health Surveys, in DHS Working Papers No. 87. 2013, ICF International: Calverton, Maryland, USA.

[7] Bocquier, P., Analyzing urbanization in sub-Saharan Africa, in New Forms of Urbanization. 2017, Routledge. p. 133-150. 
[8] Choudhury, S., J. T. Erausquin, and M. Withers, Global Perspectives on Women's Sexual and Reproductive Health Across the Lifecourse. 2018: Springer.

[9] World Health Organization, World health statistics 2017. Monitoring health for SDGs (sustainable development goals), 2017.

[10] Cleland, J. and K. Machiyama, The Challenges Posed by Demographic Change in sub-Saharan Africa: A Concise Overview. Population and Development Review, 2017. 43(S1): p. 264-286.

[11] Mbacké, C., The Persistence of High Fertility in sub - Saharan Africa: A Comment. Population and Development Review, 2017. 43(S1): p. 330-337.

[12] INSAE, Principaux Indicateurs Socio démographiques et Économiques du Bénin, (RGPH-4, 2013). 2016.

[13] ICF International, The DHS Program STATcompiler. Funded by USAID. STATcompiler. Available from: http://www.statcompiler.com/en/. 2018.

[14] INSAE and ICF International, Enquête Démographique et de Santé Bénin 2011-2012. 2013, INSAE/Bénin and ICF International: Calverton, Maryland, USA.

[15] United Nations, World Urbanization Prospects The 2014 Revision. 2014

[16] Engel, E., D. Richter, and J. Schüring, Bénin: vers une transformation rurale inclusive et durable. 2017.

[17] Anglewicz, P., J. Corker, and P. Kayembe, The fertility of internal migrants to Kinshasa. Genus, 2017. 73(1): p. 4.

[18] Akinyemi, J. O., C. O. Odimegwu, and A. S. Adebowale, The effect of internal migration, individual and contextual characteristics on contraceptive use among Nigerian women. Health care for women international, 2017. 38(10): p. 10751094.

[19] Subaiya, L., Internal migration and the use of reproductive and child health services in Peru, in DHS Working Papers No. 38. 2007, Macro International: Calverton, Maryland, USA.

[20] Khanal, M. N., et al., Impact of male migration of contraceptive use, unmet need, and fertility in Nepal: Further analysis of the 2011 Nepal Demographic and Health Survey, in DHS Further Analysis Reports No. 74. 2013, ICF International: Calverton, Maryland, USA.

[21] Cau, B. M., Female migration, local context and contraception use in urban Mozambique. African Journal of Reproductive Health, 2016. 20(1): p. 52-61.

[22] Shittu, S. B. and A. I. Akinyemi, Determinants of contraceptive use among Hausa migrants in selected urban communities of Osun State, Nigeria. IFE PsychologIA: An International Journal, 2017. 25(1): p. 266-285.

[23] Lindstrom, D. P. and C. H. Hernández, Internal migration and contraceptive knowledge and use in Guatemala. International family planning perspectives, 2006: p. 146-153.

[24] Measure DHS, Description of the demographic and health surveys individual recode data file. Calverton, MD USA: Measure DHS, 2008.

[25] Brockerhoff, M., Fertility and family planning in African cities: The impact of female migration. Journal of Biosocial Science, 1995. 27(03): p. 347-358.

[26] Sevoyan, A. and V. Agadjanian, Contraception and abortion in a low-fertility setting: the role of seasonal migration. International perspectives on sexual and reproductive health, 2013: p. 124-132.

[27] Ochako, R., et al., Modern contraceptive use among migrant and non-migrant women in Kenya. Reproductive health, 2016. 13(1): p. 67.

[28] Wang, F., Is Rapid Fertility Decline Possible? Lessons from Asia and Emerging Countries, in Africa's Population: In Search of a Demographic Dividend. 2017, Springer. p. 435-451.

[29] Kamruzzaman, M. and M. A. Hakim, Family Planning Practices among Married Women attending Primary Health Care Centers in Bangladesh. International Journal of Bioinformatics and Biomedical Engineering, 2015. 1(3): p. 251-255.

[30] Uprety, S., et al., Access to family planning services by migrant couples in Nepal-barriers and evidence gaps. 2016.

[31] Marcén, M., J. A. Molina, and M. Morales, The effect of culture on the fertility decisions of immigrant women in the United States. 2016.

[32] Chattopadhyay, A., M. J. White, and C. Debpuur, Migrant fertility in Ghana: Selection versus adaptation and disruption as causal mechanisms. Population studies, 2006. 60(2): p. 189-203.

[33] Rokicki, S., L. Montana, and G. Fink, Impact of migration on fertility and abortion: evidence from the household and welfare study of Accra. Demography, 2014. 51(6): p. 2229-2254.

[34] De Brauw, A., V. Mueller, and H. L. Lee, The role of ruralurban migration in the structural transformation of Sub-Saharan Africa. World Development, 2014. 63: p. 33-42.

[35] Khan, R., et al., The men are away: pregnancy risk and family planning needs among women with a migrant husband in Barisal, Bangladesh, in DHS Further Analysis Reports No. 98. 2016, ICF International: Rockville, Maryland, USA.

[36] Bongaarts, J. and R. G. Potter, Fertility effect of seasonal migration and seasonal variation in fecundability: Test of a useful approximation under more general conditions. Demography, 1979. 16(3): p. 475-479.

[37] Goldstein, S. and P. Tirasawat, Fertility of migrants to urban places in Thailand. 1977.

[38] Moreno, L., Residential mobility and contraceptive use in northeastern Brazil. 1993.

[39] Rutstein, S. O. and G. Rojas, Guide to DHS statistics. Calverton, MD: ORC Macro, 2006.

[40] Garcia, A. J., et al., Modeling internal migration flows in subSaharan Africa using census microdata. Migration Studies, 2015. 3(1): p. 89-110.

[41] Adebowale, S. A. and M. E. Palamuleni, Determinants of unmet need for modern contraception and reasons for non-use among married women in rural areas of Burkina Faso. Etude de la Population Africaine, 2014. 28(1): p. 499.

[42] Nair, P. S. and K. Navaneetham, Patterns and determinants of modern contraceptive use in Southern Africa. 2015, Department of population studies, university of Botswana. 
[43] Ochako, R., et al., Determinants of modern contraceptive use among sexually active men in Kenya. Reproductive health, 2017. 14(1): p. 56.

[44] Decat, P., et al., Determinants of unmet need for contraception among Chinese migrants: a worksite-based survey. The European Journal of Contraception \& Reproductive Health Care, 2011. 16(1): p. 26-35.

[45] Filmer, D. and L. H. Pritchett, Estimating wealth effects without expenditure data - or tears: an application to educational enrollments in states of India. Demography, 2001. 38(1): p. $115-132$.

[46] Kulu, H. and N. Milewski, Family change and migration in the life course: An introduction. Demographic Research, 2007. 17: p. 567.

[47] Andersson, G., Childbearing after Migration: Fertility Patterns of Foreign-born Women in Sweden. International Migration Review, 2004. 38(2): p. 747-774.

[48] Sargent, C. and D. Cordell, Polygamy, disrupted reproduction, and the state: Malian migrants in Paris, France. Social science \& medicine, 2003. 56(9): p. 1961-1972.
[49] Rutayisire, P. C., Disruptive Events and Demographic Behaviour: Explaining the Shifts in Fertility in Rwanda. 2015: Utrecht University.

[50] Brockerhoff, M. and A. E. Biddlecom, Migration, sexual behavior and the risk of HIV in Kenya. International migration review, 1999: p. 833-856.

[51] Unger, J. B., Acculturation and attitudes about contraceptive use among Latina women. Health Care for Women International, 2000. 21(3): p. 235-249.

[52] Afulani, P. A. and J. Asunka, Socialization, adaptation, transnationalism, and the reproductive behavior of subSaharan African migrants in France. Population Research and Policy Review, 2015. 34(4): p. 561-592.

[53] Sudhinaraset, M., N. Astone, and R. W. Blum, Migration and unprotected sex in Shanghai, China: correlates of condom use and contraceptive consistency across migrant and nonmigrant youth. Journal of Adolescent Health, 2012. 50(3): p. S68-S74. 